\title{
EFFECT OF SODIUM MECLOFENAMATE ON FERTILITY OF
}

\section{MALE RATS}

W. D. RATNASOORIYA

Department of Zoology, University of Colombo, Colombo, Sri Lanka

AND

N. D. W. LIONEL

Late of Department of Pharmacology, University of Colombo, Colombo, Sri Lanka.

(Date of receipt: 15 November 1984)

(Date of acceptance : 30 January 1985)

\begin{abstract}
Chronic local administration of sodium meclofenamate, a prostaglandin synthesis blocking drug, to epididymis of rats via silicone rubber rods $(3.5 \mathrm{~mm}$ dia. and $10-12 \mathrm{~mm}$ length) containing $50 \%$ drug produced an irreversible suppresssion in fertility. This effect was accompanied by a reduction in libido, ejaculatory competence, motility of epididymal sperm and the weights of seminal vesicles and coagulatory glands. Furthermore, mild to moderate necrosis in tunica vaginalis and scrotal sacs was evident. However, a lower dose (25\% rods) failed to induce any significant change in fertility nor did it produce any of the above undesirable side effects.
\end{abstract}

\section{Introduction}

Prostaglandins are present in vasa deferentia and epididymides of several species ${ }^{4,8}$ including the rat. $^{7}, 10$ Although the precise role of prostaglandins in epididymal function is unknown, it is suggested that they are involved in regulation of their spontaneous contractions, ${ }^{7}$ orgasmic contraction ${ }^{11,12}$ and processes of maturation of sperm within it. ${ }^{14}$ It should therefore be possible to alter fertility potential of males by prostaglandin synthesis blocking drugs. Indeed, a reduction in fertility of male rats has been demonstrated with chronic local application of aspirin, a prostaglandin synthesis blocking drug to epididymis. ${ }^{15}$ However, the antifertility efficacy of aspirin in this study was found to be low. The present study was therefore, undertaken to investigate the effects of a therapeutically more potent prostaglandin synthesis blocking drug, sodium meclofenamate when administered locally to epididymis of rats. Sodium meclofenamate (Meclomen ${ }^{\circledR}$; N-(2,6dichloro-m-tolyl) anthranilic acid, sodium salt, monohydrate; WarnerLambert Co., U.S.A.) is the most potent known inhibitor of prostaglandin synthesis in synthetase systems of mammalian origin. ${ }^{9}$ 


\section{Experimental}

\subsection{Animals}

Healthy adult laboratory bred mixed strain rats of proven fertility (males weighing 275 - $300 \mathrm{~g}$ and females weighing $200-225 \mathrm{~g}$ ) were used. They were housed in a well ventilated animal house at a temperature of $28-30^{\circ} \mathrm{C}$ with a natural photoperiod (approximately $12 \mathrm{~h}$. light and $12 \mathrm{~h}$. dark daily). All rats had free access to food (rat pellets, Moosajees Ltd., and green leaves) and tap water.

\subsection{Construction of sustained-release drug delivery system}

Silastic formulations containing $25 \%$ and $50 \%$ sodium meclofenamate were prepared in the form of rods $(3.5 \mathrm{~mm}$, dia. and $10-12 \mathrm{~mm}$, length) by mixing known weights of powdered sodium meclofenamate and polysiloxane polymer (silastic 382, Medical Grade Elastomer, Dow Coming Corp. Midland, Michigan, U.S.A.) in a pestle and mortar, followed by the addition of the curing agent (stannous octoate). The resulting homogeneous mixture was expressed from a $5 \mathrm{ml}$ disposable syringe into polythene tubing and allowed to set. Control rods consisting entirely of silastic were also prepared.

\subsection{Insertion of rods to epididymis}

Insertion of rods was made under mild ether anaesthesia using aseptic precautions. A rod containing $50 \%$ sodium meclofenamate (13 rats), or $25 \%$ sodium meclofenamate $(6$ rats) or a drug-free rod (10 rats) was placed adjacent to each epididymis via an incision made in the scrotal sac and in the tunica vaginalis of each side as described in detail elsewhere. ${ }^{16}$ The day of insertion of rod was designated as day $O$.

\subsection{Assessment of fertility}

Libido, ejaculatory competence and fertility of the operated animals were tested on day 3 and 7 and then approximately at weekly intervals for 2 months by pairing each male overnight with a pro-oestrous female, which had had a regular 4 day vaginal cycle. Insemination was confirmed by the presence of spermatazoa in the oestrous vaginal smear on the following morning (between 7.00 and 8.00 a.m.). If spermatazoa were present their numbers in the vagina were estimated. In the absence of spermatozoa daily vaginal smearing of the females was continued to check pregnancy. or pseudopregnancy. At $8-10$ days post coitum, the females were laparotomized and the number of embryos present in each uterine horn was counted. 


\subsection{Motility of epididymal spermatozoa}

Motility was assessed in a separate series of experiments with 6 rats, each of which was fitted with one $50 \%$ sodium meclofenamate rod adjacent to one epididymis and one drug-free adjacent to contralateral epididymis. At day 7 , these rats were anesthetized and spermatozoa from a portion of the cauda epididymis were extracted into saline $(\mathrm{NaCl} 9 \mathrm{~g} / \mathrm{l})$ and their motility graded on a subjective scale from 0 (immotile) to 5 (greatest motility ever observed). In addition, these spermatozoa were examined microscopically (x 400) for major abnormalities.

\subsection{Reproductive organ weights and $\mathrm{pH}$ determinations}

Six rats were fitted with a single $50 \%$ sodium meclofenamate rod adjacent to each epididymis and 6 with a single drug free rod adjacent to each epididymis. On day 7 , the animals were killed, weighed and their testes, epididymidis, vasa deferentia, seminal vesicles and coagulatory glands were excised, defatted, blotted free of any blood and weighed separately on a Mettler analytical balance. The weights of these organs are represented as a percentage of body weight. Equal weights of seminal vesicle of the treated and the control rats were then homogenized with $10 \mathrm{ml}$ distilled water and $\mathrm{pH}$ of these were assessed using a Beckman $\mathrm{pH}$ meter.

\subsection{Autopsy}

On day 60 , all survivors (26 rats) were sacrificed and their gastrointestinal tract and reproductive systems were examined grossly for any abnormalities. The 3 rats which died on day 3 were also subjected to an identical procedure.

\subsection{Nerve-induced mechanical response of isolated vasa deferentia}

In 6 rats, vasa deferentia were rapidly removed under mild ether anaesthesia and carefully cleaned from loose connective tissue and fat. The preparations were mounted at $1.0 \mathrm{~g}$ tension in a $50 \mathrm{ml}$ organ bath maintained at $37 \pm .1^{\circ} \mathrm{C}$ in a physiological salt solution of the following composition $(\mathrm{mM} / \mathrm{l})$. $\mathrm{Na}^{+}$, $143 ; \mathrm{K}^{+}, 5.8 ; \mathrm{Ca}^{++}, 2.6 ; \mathrm{Mg}^{++}, 1.2 ; \mathrm{Cl}^{-}, \mathrm{I}_{2} 2 ; \mathrm{H}_{2} \mathrm{PO}_{4}^{-}, 1.2 ; \mathrm{HCO}_{3}-\mathrm{Cl}_{2}$ : $\mathrm{SO}_{4}--, 1.2$ and glucose 11.1 . The solution in the organ bath was continuously bubbled with $5 \% \mathrm{CO}_{2}$ in $\mathrm{O}_{2}$. Contractions were elicited by transmural stimulation through platinum ring electrodes using SRI stimulator for $5 \mathrm{sec}$ at a frequency of $5 \mathrm{H}_{z}$ with impulses of $0.5 \mathrm{~m}$. sec duration and $90 \mathrm{~V}$ and recorded ismoterically on a tioscience pen recorder. Sodium meclofenamate was then added cumulatively, increasing the concentration every 
$15 \mathrm{~min}$. and response to electrical stimulation was recorded at each dose studied $(2,10,20,50$ or $100 \mu \mathrm{g} / \mathrm{ml})$. Contractile response in the presence of drug were expressed as a percentage reduction of the organs response to transmural stimulation prior to drug addition.

\subsection{Release rate from $50 \%$ sodium meclofenamate rods}

A single weighed $50 \%$ sodium meclofenamate rod was fitted adjacent to each epididymis of 6 rats. These rods were removed on day 8 and dried at $60^{\circ} \mathrm{C}$ until a constant weight was reached. The quantity of drug released during this period was estimated by substracting the final weight from the initial weight. The release rate was then computed assuming a constant release profile from the rod. However, this is, at best, an approximate estimation.

\section{Results}

During the study, 3 rats fitted with $50 \%$ sodium meclofenamate rods died; the first on day 2 and the others on day 3. The cause of death appears to be drug-related as autopsy revealed lesions representing gastrointestinal intolerance and peritonitis. These 3 rats were excluded from the present study. The general appearance of the majority of the remaining animals was normal as was evident by their behavioural responses and undiminished food and water intake. However, 6 rats fitted with $50 \%$ sodium meclofenamate rods developed, between day $20-35$, mild to moderate bilateral necrosis in the areas of tunica vaginalis and scrotal sacs adjacent to the site of implantation of the rod.

\subsection{Assessment of fertility}

The $50 \%$ sodium meclofenamate rods caused a marked impairment of libido as was indicated by complete absence of spermatozoa in vaginal smears and by the absence of the pseudopregnant state of the females paired with treated males ; 19 out of 58 pairings did not result in successful mating. In contrast, in $25 \%$ sodium meclofenamate and control groups successful mating took place in 26 out of 30 and 87 out of 88 pairings respectively. Furthermore, at successful matings, the vaginal sperm counts of $50 \%$ sodium meclofenamate group was less than 0.1 million, while that of $25 \%$ sodium meclofenamate and control groups exceeded 5 million.

The fertility of the $25 \%$ sodium meclofenamate and control groups was unimpaired throughout the study as indicated by the normal complement of embryos $(6-11)$ in the females with which they were paired. On the other hand, in $50 \%$ sodium meclofenamate group, fertility was reduced in 


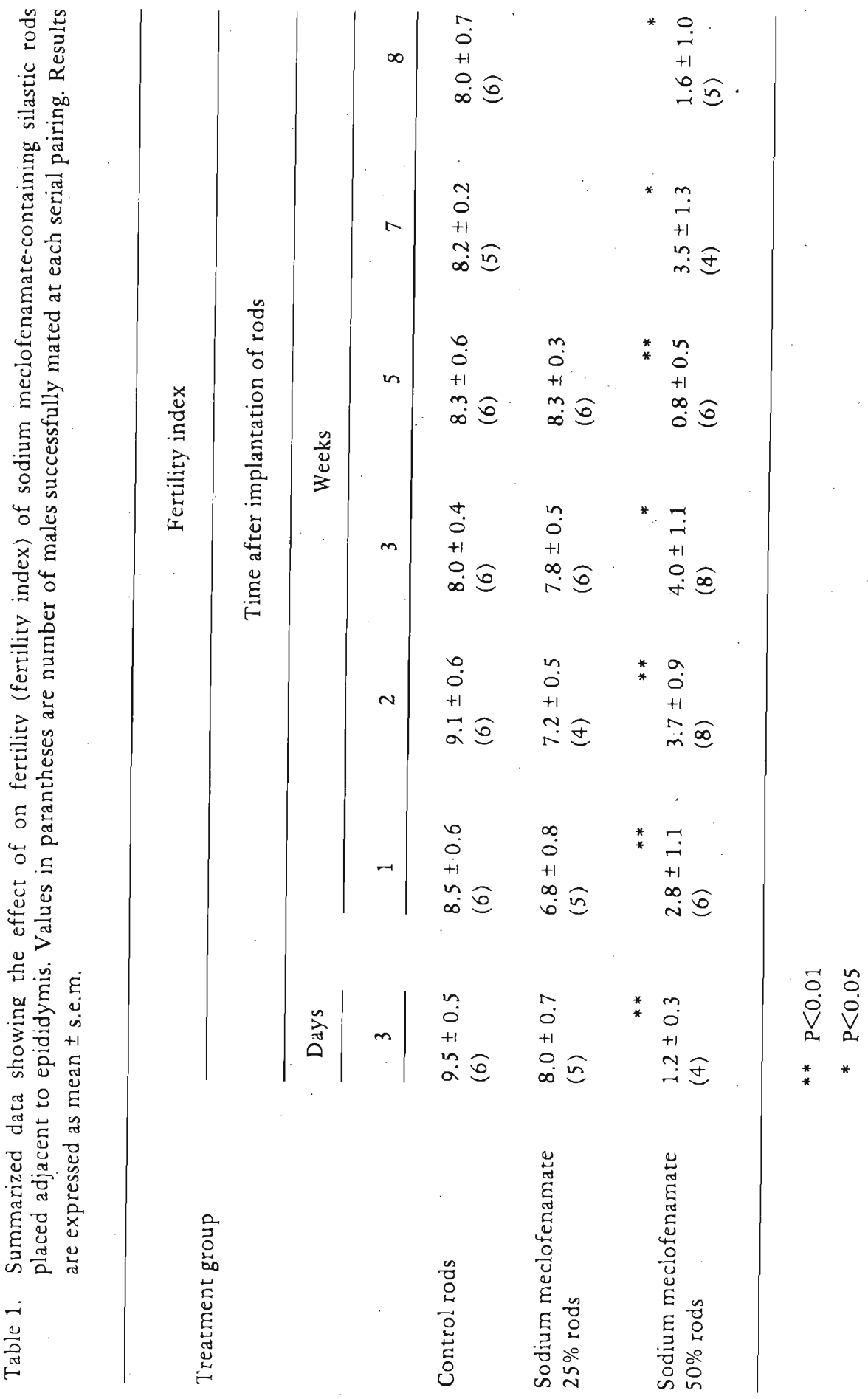


all animals; no embryos were detected in 19 pairings while low numbers $(3-7)$ were observed at 21 pairings. The fertility was restored to normal level only in one animal in this treatment group. These data are summarized by calculating at each time interval, the fertility index, where fertility index $=$ total number of embryos/number of successful matings at that time interval. The summary Table 1 shows that there is a significant reduction in the fertility index of animals treated with $50 \%$ sodium meclofenamate (Mann-Whitney test, $\mathrm{P}<0.05)$.

\subsection{Motility of epididymal spermatozoa}

The average motility score of sperm on the treated side was $2.50 \pm 0.22$ (mean \pm s.e.m.) and that on the control side was $4.67 \pm 0.21$. This difference was statistically significant $(\mathrm{P}<0.05$, Mann-Whitney test). Further, there were no major morphological abnormalities in spermatozoa of the treated side.

\subsection{Reproductive organ weights and $\mathrm{pH}$ measurements}

The average weights of testes, epididymidis, vasa deferentia, seminal vesicles and coagulatory glands and $\mathrm{pH}$ of seminal vesicular homogenate of $50 \%$ sodium meclofenamate treated rats were $1157 \pm 33 \mathrm{mg}, 450 \pm 33 \mathrm{mg}, 99 \pm$ $08 \mathrm{mg}, 229 \pm 34 \mathrm{mg}$ and $33 \pm 04 \mathrm{mg}$ and $6.37 \pm 0.04$ respectively. In the control rats, corresponding values were $1089 \pm 40 \mathrm{mg}, 420 \pm 20 \mathrm{mg}, 83 \pm$ $07 \mathrm{mg}, 394 \pm 32 \mathrm{mg}$ and $93 \pm 27 \mathrm{mg}$ and $6.4 \pm 0.09$. A significant reduction in the weights of seminal vesicles $(\mathbf{P}<0.02)$ and coagulatory glands $(P<0.05)$ was evident with Student unpaired t-test.

\subsection{Autopsy}

The 3 rats that died cluring drug treatment (50\% rods) had gastric and intestinal lesions. Ulceration of gastrointestinal tract as a side effect has been reported in rats following chronic oral administration of sodium meclofenamate in high doses. ${ }^{20}$ The cauda epididymidis of rats with $50 \%$ sodium meclofenamate rocls were distended and 5 animals had developed bilateral spermatic granulomas. The vasa defcrentia, on the other hand, were devoid of any sperm granulomas. In contrast, the abclominal viscera and reproductive organs of $25 \%$ sodium ineclolenamate and control group appeared normal and no granulomas were observed in the epididymidis and vasa deferentia. Furthermore, the silastic rods in all rats remained adjacent to epididymidis without much displacement from their original positions. 


\subsection{Nerve-induced mechanical response of isolated vasa deferentia}

The vasa deferentia responded to nerve stimulation by eliciting an initial rapid 'twitch' (amplitude, $3.4 \pm 0.25 \mathrm{~g}$ ) and secondary sustained contraction (amplitude, $1.23 \pm 0.15 \mathrm{~g}$ ) as reported by other workers. ${ }^{2,18}$ As shown in Table 2 sodium meclofenamate significantly depressed both components of the response, from above $10 \mu \mathrm{g} / \mathrm{ml}(\mathrm{P}<0.05$, paired t-test).

Table 2: Effect of sodium meclofenamate on the isometric longitudinal response to nerve stimulation. Responses are expressed as a percentage reduction of pre-drug control mean \pm s.e.m. $(\mathrm{N}=10-12)$

\begin{tabular}{|c|c|c|}
\hline \multirow{2}{*}{$\begin{array}{l}\text { Concentration of } \\
\operatorname{drug}(\mu \mathrm{g} / \mathrm{ml})\end{array}$} & \multicolumn{2}{|c|}{ Response ( \% reduction ) } \\
\hline & Twitch & Secondary \\
\hline 2 & $7.1 \pm 4.8$ & $9.3 \pm 1.5$ \\
\hline 10 & $42.2 \pm 5.5$ & $44.0 \pm 10$ \\
\hline 20 & $46.6 \pm 7.1$ & $56.8 \pm 6.2$ \\
\hline 50 & $44.3 \pm 6.1$ & $48.6 \pm 8.5$ \\
\hline 100 & $56.0 \pm 6.7$ & $64.2 \pm 4.1$ \\
\hline
\end{tabular}

\subsection{Release rate from $50 \%$ sodium meclofenamate rods}

The average rate of relcase of drug per day from $50 \%$ sodium meclofenamate rods was $8.4 \pm 0.6 \mathrm{mg}$.

\section{Discussion}

The results of the present study show that chronic insertion of silastic rods containing $50 \%$ sodium meclofenamate rods adjacent to epididymis of rats calused a reduction in fertility and libido. Both these effects were permanent throughout the pcriod of study. A lower dose of drug (25\% rods), neither suppressed fertility nor libido. In contrast, aspirin when applied locally to epididymis of rats has been shown to reduce fertility with no concomitant reduction in libido. 15

Several factors may have contributed for the antifertility effect observed in the study, but the production oligospermic ejaculates is probably the principal factor. At the initial phase (up to about 21 days) of the study, such an cffect could hare resulted from an impairment of ejaculation, which is consistent with the observation that sodium meclofenamate reduced 
considerably nerve-induced contractions of isolated vasa deferentia. Moreover, in therapeutic doses, naparoxen, another prostaglandin synthesis blocking drug has been reported to cause impairment of ejaculation in men. ${ }^{19}$ In view of the present method of administration and high release rate of drug (approximately $9 \mathrm{mg} /$ day) injury or physiological changes in the nerves and smooth muscle of the epididymis may occur. This too may have contributed, to the production of oligospermic ejaculates as disturbances in ejaculatory phenomenon is reported with injury or alteration of the nerves and muscles supplying the ejaculatory system. ${ }^{19}$ Infertility at subsequent stages could have resulted from an impairment in spermatogenesis or due to blockage of sperm transport from mechanical occlusions in the epididymal tubules by the sperm granulomas which were evident in majority of the animals treated with 50\% sodium meclofenamate. The former mechanism is unlikely as prostaglandin synthesis inhibitors promote spermatogenesis ${ }^{1}$ and prostaglandins suppress spermatogenesis. ${ }^{1}$ The lack of restoration of fertility in treated males (50\% rods) can be attributed to sperm granulomas in cauda epididymis, as it is known that sperm granulomas impair fertility permanently. ${ }^{3}$ There is no conclusive evidence about the mechanism/s responsible for the reduction in libido observed in the study, but it is likely to be due to a reduction in androgen output from testes since a significant depression in wet weights of seminal vesicles and coagulatory glands was observed. Male libido ${ }^{13}$ and structural and functional integrity of sexual accessory glands are androgen-dependent. ${ }^{5,13}$ At later stages of study (after day 20) in particular, physical trauma arising from drug-induced lesions in the tunica vaginalis and in scrotal sacs may have been partly responsible for the suppression in libido as it is known that discomfort at site of sperm granulomas occur during sexual excitement of ejaculation ${ }^{17}$ and that stress, physical or mental, decline sexual drive in men. ${ }^{6}$ In addition, it is likely that impairment of sperm motility together with a change in biochemistry of semen and fertilizing potential of sperm may have played a substiantial role in inducing the observed antifertility effects. Alteration in semen biochemistry and fertilizing capacity of ejaculated sperm but not in sperm numbers or sperm motility has been suggested as possible mechanism for antifertility recorded with local application of aspirin to epididymis. ${ }^{15}$

In conclusion, this study provides confirmation that prostaglandin synthesis inhibiting drugs reduce fertility of male rats when administered locally to epididymis, previously shown with aspirin. ${ }^{15}$ Further, although aspirin and sodium meclofenamate are both prostaglandin synthesis inhibitors bringing about antifertility effects in male rats, it becomes evident that they operate via different mechanisms. 


\section{Acknowledgements}

Authors are thankful to Dr. S. U. K. Ekaratne, Department of Zoology, University of Colombo, Sri Lanka, for critically reading the manuscript and Dr. M. L. Black, Warner-Lambert Company, U S A for the generous gift of sodium meclofenamate. This work was supported by a grant from the Natural Resources, Energy and Science Authority of Sri Lanka (Grant No. 80/56).

\section{References}

1. ABBAtiello, E.R., KAMINSKY, M. \& WEISBROTH, S. (1975) Int. J. Fert. 20: 177-182

2. ANTON, P.G., DUNCAN, M.E. \& McGRATH, J.C. (1977) J. Physiol. 273: 23-43

3. AOOKER, R.H. \& DAVIS, B.K. (1975) In control of male fertility (Eds.) Sciarra, J.J., Markland, C. \& Speidel, J.J., Harper \& Row, New York: 249-261

4. BARTKE, A. \& KOERNER, S. (1974) Endocrinology 95:1739-1745

5. BEACH, F. \& WESBROOK, W. (1968) J. Endocr. 42: 379-381

6. BHARDWAJ, K.S. \& VIMANI, R. (1970) Panjab Med. J. 19 (12): 439-441

7. COESTiNo, M.J., TAKihARA, H., BURHOP, J.W. \& COCKETT, A.T.K. (1984) J. Androl. 5: $216-222$

8. EliASSON, R. (1959) Acta Pbysiol. Scand. 46 Suppl. 158:1-73

9. FOWLER, R.J. \& VANE, J.R. (1974) In prostaglandin synthetase inbibitors Eds. Robinson, H.J. \& Vane, J.R., Reven Press, New York: 9-18

10. GEROZISSIS, K. \& DRAY, F. (1977) J. Reprod. Fert. 50: 113-115

11. MARLEY, P.B. \& Smith, C.C. (1974(a)) J. Endocr. 61: XXIV

12. MARLEY, P.B. \& SMITH, C.C. (1974(b)) Br. J. Pharmac. 52: 114 p

13. NEUMANN, F. (1977) Horm. Metab. Res. 9: 1-13

14. POUlOS, A., VOGLMAYR, J.K. \& WHITE, I.G. (1973) Biocbem. biopbys, Acta 306: 194202

15. RATNASOORIYA, W.D. \& LIONEL, N.D.W. (1984) Ind. J. exp. Biol. 22: 75-77

16. RATNASOORIYA, W.D., GILMORE, D.P. \& WADSWORTH, R.M. (1980) J. Reprod. Fert. 58: $19-25$

17. SCHMIDT, S.S. (1979) Fertil. Steril. 31 (2): 178-181

18. SWEDIN, G. (1971) Acta Pbysiol. Scand. Suppl. 369: 1-34

19. THOMAS, A.J. (1983) Fertil. Steril. 39(4): 445-454

20. WAX, J.M.S. (1978) Cur. Ther. Resh. 23(4):3-13 